\title{
ANALISIS FAKTOR-FAKTOR YANG MEMPENGARUHI AUDIT JUDGMENT PADA AUDITOR
}

\author{
Michelle Meivina Putry Limen ${ }^{1}$, Herman Karamoy $^{2}$, Hendrik Gamaliel $^{3}$ \\ ${ }^{1,2,3}$ Akuntansi, Fakultas Ekonomi \& Bisnis, Universitas Sam Ratulangi, Alamat, Kota, Kode Pos, Negara \\ E-mail : michellempl@yahoo.co.id
}

\begin{abstract}
Audit Judgment is auditor's policy in giving an opinion on the information found along the audit process, which refers to an idea, a notion or an estimation about events that happened on the audit object. The outcome that is issued by an auditor has to be able to provide the right information and evidence thus the delivered audit judgment will be correct or will fit. Therefore, it's important to know which factors are able to influence the audit judgment. This research aims to empirically test the influence of the pressure of obedience, task complexity and audit experience on the quality of audit judgment. Research was held on two objects, which were Ariesman Auly Public Accounting Firm Manado and Badan Pengawas Keuangan dan Pembangunan (BPKP) Provinsi Sulawesi Utara. Total of obtained samples were 30 auditors. The used sampling method was Ordinal Regression Analysis. The result of this research shows that the pressure of obedience influences audit judgment significantly, while task complexity and audit experience do not have significant influence on audit judgment.

Keywords : pressure of obedience, task complexity, auditing experience, audit judgment, ordinal regression analysis
\end{abstract}

\section{PENDAHULUAN}

Dewasa ini, kebutuhan akan jasa audit independen sudah tidak dapat dipungkiri lagi. Dengan begitu banyaknya perusahaan yang berdiri di Indonesia, banyak pula yang memerlukan dasar pengambilan keputusan bisnis yang relevan dan terpercaya, sehingga tuntutan untuk memiliki laporan keuangan yang diaudit oleh auditor independen menjadi lebih tinggi. Begitu juga dengan perusahaan-perusahaan yang memerlukan modal dalam jumlah yang banyak untuk mendukung kelangsungan operasinya, laporan keuangan yang sudah diaudit oleh auditor independen merupakan salah satu syarat utama bagi mereka untuk mendapatkan pinjaman dari bank dan untuk go public di pasar modal.

Audit atau pemeriksaan dalam arti luas bermakna evaluasi terhadap suatu organisasi, sistem, proses, atau produk. Audit dilaksanakan oleh pihak yang kompeten, objektif, dan tidak memihak, yang disebut auditor. Tujuannya adalah untuk melakukan verifikasi bahwa subjek dari audit telah diselesaikan atau berjalan sesuai dengan standar, regulasi, dan praktik yang telah disetujui dan diterima. Menurut Arens dan Loebbecke (2003), auditing adalah "suatu proses pengumpulan dan pengevaluasian bahan bukti tentang informasi yang dapat diukur mengenai suatu entitas ekonomi yang dilakukan seorang yang kompeten dan independen untuk dapat menentukan dan melaporkan kesesuaian informasi dengan kriteriakriteria yang telah ditetapkan".

Auditor harus punya prinsip tidak akan terpengaruh dan tidak dipengaruhi oleh berbagai kekuatan yang berasal dari luar diri auditor dalam mempertimbangkan fakta yang dijumpainya dalam pemeriksaan (Praditaningrum, 2012). Dalam proses audit atas laporan keuangan dan pemberian opini, dibutuhkan judgment. Audit judgment adalah kebijakan auditor dalam menentukan pendapat mengenai hasil auditnya yang mengacu pada pembentukan suatu gagasan, pendapat atau perkiraan tentang suatu objek, peristiwa, status, 
atau jenis peristiwa lainnya (Jamilah dkk., 2007). Auditor membuat judgment dalam mengevaluasi pengendalian intern, menilai risiko audit, merancang dan mengimplementasikan penyampaian dan menilai serta melaporkan aspek-aspek ketidakpastian (Indarto, 2011). Secara umum, terdapat beberapa faktor yang mempengaruhi audit judgment yang dihasilkan oleh auditor, seperti tekanan ketaatan yang dialami auditor, kompleksitas tugas yang dihadapi auditor, dan pengalaman auditor. Audit judgment merupakan suatu pertimbangan yang mempengaruhi dokumentasi bukti dan keputusan yang dibuat oleh auditor (Taylor, 2000; dalam Sabaruddinsah, 2007), sehingga diperlukan kejujuran perusahaan dalam menyajikan laporan keuangan dan auditor dalam melakukan auditing.

Tekanan ketaatan adalah kondisi seorang auditor yang dihadapkan pada dilema penerapan standar audit. Tekanan ketaatan timbul karena pengaruh tekanan atasan pada konsekuensi yang memerlukan biaya, seperti halnya tuntutan hukum, hilangnya profesionalisme dan hilang kepercayaan publik dan kredibilitas sosial (Hartono, 1999; dalam Jamilah dkk., 2007).

Kompleksitas tugas adalah tugas yang kompleks, yang terdiri atas bagian-bagian yang banyak, berbeda-beda dan saling terkait satu dengan yang lain. Semakin kompleks tugas yang dihadapi oleh seorang auditor maka semakin sulit baginya untuk memberikan penilaian yang cepat dan akurat (Struart, 2001; dalam Tielman, 2012). Bonner (1994 : 221) menyatakan bahwa semakin kompleks tugas yang dihadapi oleh seorang auditor maka akan semakin sulit baginya untuk memberikan penilaian yang cepat dan akurat.

Pengalaman auditor adalah kemampuan auditor dalam memprediksi dan mengevaluasi suatu kejadian di perusahaan yang akan diaudit. Libby (1995, dalam Tielman, 2012) menyatakan bahwa judgment seseorang dapat diukur dengan unsur pengalaman kerja seorang auditor. Kompetensi tekhnis berupa pengalaman auditor merupakan kemampuan individu dan dianggap menjadi faktor penting dalam mengambil judgment. Berdasarkan jenis audit, pengetahuan dan pengalaman akan membantu dalam pengambilan keputusan (Abdolmohammadi dan Wright, 1987 dalam Martinov dan Pflugrath, 2008).

\section{TINJAUAN PUSTAKA}

\subsection{Kajian Teori}

\subsubsection{Teori Pengambilan Keputusan}

Keputusan menurut Ralph C. Davis adalah hasil pemecahan masalah yang dihadapinya dengan tegas. Suatu keputusan merupakan jawaban yang pasti terhadap suatu pertanyaan. Keputusan harus menjawab pertanyaan tentang apa yang dibicarakan dalam hubungannya dengan perencanaan. Keputusan dapat pula berupa tindakan terhadap pelaksanaan yang sangat menyimpang dari rencana semula.

\subsubsection{Standar Auditing}

Standar Auditing adalah sepuluh standar yang ditetapkan dan disahkan oleh Institut Akuntan Publik Indonesia (IAPI), yang terdiri dari standar umum, standar pekerjaan lapangan, dan standar pelaporan beserta interpretasinya.

\subsubsection{Tekanan Ketaatan}

Menurut Jamilah, dkk (2007), tekanan ketaatan merupakan kondisi dimana seorang auditor dihadapkan pada sebuah dilema penerapan standar profesi auditor. Tekanan ketaatan dapat diukur dengan keinginan untuk tidak memenuhi keinginan klien untuk berperilaku menyimpang dari standar profesional akan menentang klien karena menegakkan profesionalisme dan akan menentang atasan jika dipaksa melakukan hal yang bertentangan dengan standar profesional dan moral (Jamillah dkk, 2007).

\subsubsection{Kompleksitas Tugas}


Kompleksitas tugas merupakan tugas yang tidak terstruktur, membingungkan dan sulit (Sanusi dalam Cecilia, 2007). Jamilah, dkk. (2007) menjelaskan terdapat dua aspek penyusun dari kompleksitas tugas, yaitu tingkat kesulitan tugas dan struktur tugas. Tingkat sulitnya tugas selalu dikaitkan dengan banyaknya informasi tentang tugas tersebut, sementara struktur tugas adalah terkait dengan kejelasan informasi (information clarity).

\subsubsection{Pengalaman Audit}

Knoers dan Haditono (1999) mengatakan bahwa pengalaman kerja merupakan suatu proses pembelajaran dan penambahan perkembangan potensi bertingkah laku baik dari pendidikan formal maupun non formal atau bisa juga diartikan sebagai suatu proses yang membawa seseorang kepada suatu pola tingkah laku yang lebih tinggi.

\subsubsection{Audit Judgment}

Audit judgment adalah pertimbangan auditor dalam menanggapi informasi yang ada yang akan memperngaruhi opini akhir dalam suatu pelaporan audit. Pertimbangan pribadi auditor tersebut dapat dipengaruhi oleh berbagai faktor, salah satunya adalah faktor perilaku individu. Menurut Mulyadi (2002) audit judgment adalah kebijakan auditor dalam menentukan pendapat mengenai hasil auditnya yang mengacu pada pembentukan suatu gagasan, pendapat atau perkiraan tentang suatu objek, peristiwa, status, atau jenis peristiwa lain.

\subsection{Penelitian Terdahulu}

Penelitian terdahulu menyangkut pengaruh tekanan ketaatan, kompleksitas tugas dan pengalaman auditor terhadap audit judgment yang dijadikan acuan dalam penyusunan penelitian ini memiliki hasil yang berbeda-beda seperti halnya dalam penelitian yang dilakukan oleh Ayudia (2015) yang menyatakan bahwa tekanan ketaatan berpengaruh negatif terhadap audit judgment yang diambil auditor, sedangkan Anugraheni (2014) menyatakan bahwa tekanan ketaatan tidak berpengaruh terhadap audit judgment.

\subsection{Hipotesis}

$\mathrm{H}_{0}$ : tekanan ketaatan, kompleksitas tugas dan pengalaman audit mempengaruhi audit judgment secara signifikan

\section{METODE PENELITIAN}

\subsection{Jenis dan sumber data}

penelitian ini merupakan penelitian deskriptif dan kuantitatif.

\subsection{Sampel dan teknik pengambilan sampel}

Sampel yang diambil berjumlah 10 orang dari Kantor Akuntan Publik Ariesman Auly dan 20 orang dari Badan Pengawasan Keuangan dan Pembanguan Provinsi Sulawesi Utara. Penentuan sampel dilakukan secara random sampling.

\subsection{Metode analisis}

Dalam penelitian ini, metode analisis yang digunakan adalah metode regresi logistik ordinal. 


\section{HASIL ANALISIS DAN PEMBAHASAN \\ 4.1. Hasil analisis \\ Model Fitting Information}

Tabel 1

Model Fitting Information

\begin{tabular}{|c|c|c|}
\hline Model & $\begin{array}{c}-2 \text { Log } \\
\text { Likelihood }\end{array}$ & Chi-Square \\
\hline Intercept Only & 56,601 & 19,233 \\
\hline Final & 37,368 & 1 \\
\hline
\end{tabular}

Sumber: Output SPSS, 2017

Model Fitting Information digunakan untuk menyediakan parameter model dimana kecocokkan model diperhitungkan. Model Fitting Information menguji pengaruh setiap variabel independen. Pengujian ini dilakukan untuk membandingkan nilai antara -2 Log Likelihood (-2LL) pertama (intercept only) dengan -2 Log Likelihood (-2LL) pada model final. Pada tabel 1, -2 Log Likelihood menunjukkan bahwa tanpa memasukkan variabel independen (intercept only) nilainya adalah 56,601. Sedangkan ketika vairabel independen dimasukkan (final) terdapat penurunan nilai menjadi 37,368. Perubahan nilai ini merupakan nilai Chi-Square yaitu 19,233.

\section{Uji Goodness of Fit}

\section{Tabel 2}

Goodness-of-Fit

\begin{tabular}{|c|c|c|}
\hline & Chi-Square & Sig. \\
\hline Pearson & 41,279 & 0,458 \\
\hline Deviance & 37,368 & 0,633 \\
\hline
\end{tabular}

Sumber: Output SPSS, 2017

Pengujian Hipotesis Kompatibilitas (Goodness of Fit) merupakan pengujian hipotesis untuk menentukan apakah suatu himpunan frekuensi yang diharapkan sama dengan frekuensi yang diperoleh dari suatu distribusi. Goodness of Fit akan menentukan apakah model yang digunakan cocok atau tidak. Berdasarkan tabel 2, ada dua statistik yaitu Pearson dan Deviance yang memiliki nilai chi-square masing-masing. Pearson memiliki nilai 41,279 dengan Sig 0,458 (> 0,05) dan Deviance 37,368 dengan Sig 0,633 (> 0,05).

Tabel 3

Pseudo R-Square

\begin{tabular}{|c|c|}
\hline Cox and Snell & 0,473 \\
\hline Nagalkerke & 0,558 \\
\hline McFadden & 0,340 \\
\hline
\end{tabular}

Sumber: Output SPSS, 2017

Tabel Pseudo R-Square menunjukkan bahwa seberapa besar variabel independen (Tekanan Ketaatan, Kompleksitas Tugas dan Pengalaman Audit) mampu menjelaskan variabel dependen (Audit Judgment). Terdapat Analisis McFadden, Nagelkerke dan Cox and Snell yang dimaksudkan untuk mensimulasi analisis yang di R-Square. Tabel 3 menunjukkan bahwa diantara seluruh Pseudo R-Square, Nagelkerke memiliki nilai tertinggi dengan angka 
sebesar 0,558. Hal ini menunjukkan bahwa tekanan ketaatan, kompleksitas tugas dan pengalaman audit (variabel independen) mampu menjelaskan Audit Judgment (variabel dependen) sebesar 55,8\% sedangkan sisa 44,2\% dijelaskan oleh faktor-faktor lain yang tidak dibahas dalam penelitian ini.

Tabel 4

Parameter Estimates

\begin{tabular}{|c|l|r|r|r|}
\hline & & Estimate & Wald & Sig. \\
\hline Threshold & $\begin{array}{l}\text { [Audit } \\
\text { Judgment = 1] }\end{array}$ & $-54,417$ & 58,775 & 0 \\
\hline Location & $\begin{array}{l}\text { [Audit } \\
\text { Judgment = }]\end{array}$ & $-50,196$ & 57,140 & 0 \\
\hline & $\begin{array}{l}\text { Tekanan } \\
\text { Ketaatan }\end{array}$ & $-3,835$ & 3,858 & 0,50 \\
\hline & $\begin{array}{l}\text { Kompleksitas } \\
\text { Tugas }\end{array}$ & 1,600 & 0,798 & 0,372 \\
\hline & $\begin{array}{l}\text { Pengalaman } \\
\text { Audit }\end{array}$ & 0,849 & 1,381 & 0,240 \\
\hline
\end{tabular}

Sumber: Output SPSS, 2017

Tabel Parameter Estimates membahas tentang hubungan antara variabel-variabel penjelas dengan hasil. Tabel 4 menguraikan nilai Wald dari setiap variabel independen dan signifikansinya. X1 (Tekanan Ketaatan) memiliki nilai Wald sebesar 3,858 dengan Sig. 0,05, X2 (Kompleksitas Tugas) memiliki nilai Wald sebesar 0,798 dengan Sig. 0,372 (> 0,05) dan X3 (Pengalaman Audit) memiliki nilai Wald sebesar 1,381 dengan Sig. 0,240 (> 0,5). Berdasarkan analisis, rumus untuk model regresi ordinal dalam penelitian ini dapat ditampilkan sebagai berikut :

$$
\mathrm{AJ}=\frac{\mathrm{e}^{-54,417-3,835 \mathrm{TK}+1,6 \mathrm{KT}+0,849 \mathrm{PA}}}{1+\mathrm{e}^{-54,417-3,835 \mathrm{TK}+1,6 \mathrm{KT}+0,849 \mathrm{PA}}}
$$

Dimana $\quad A J \quad=$ Audit Judgment

$T K \quad=$ Tekanan Ketaatan

$K T \quad=$ Kompleksitas Tugas

$P A \quad=$ Pengalaman Audit

\section{Interpretasi}

1. Tekanan Ketaatan (X1) memiliki pengaruh signifikan terhadap Audit Judgment (Y). Hasil untuk Tekanan Ketaatan adalah nilai Estimate sebesar -3,835, nilai Wald sebesar 3,858 dan Significance 0,05. Hasil pengolahan data ini menunjukkan bahwa variabel independen Tekanan Ketaatan memiliki pengaruh signifikan terhadap variabel dependen Audit Judgment. Nilai Odds Ratio untuk variabel Tekanan Ketaatan adalah;

OR $T K=$

$$
\begin{aligned}
& = \\
& =0,0216
\end{aligned}
$$

Artinya, probabilitas Tekanan Ketaatan mempengaruhi Audit Judgment adalah sebesar 0,0216 kali atau 2,16\%.

2. Kompleksitas Tugas (X2) tidak memiliki pengaruh signifikan terhadap Audit Judgment (Y). Hasil untuk Kompleksitas Tugas adalah nilai Estimate sebesar 
1,600, nilai Wald sebesar 0,798 dan Significance sebesar 0,372 (>0,05). Hasil pengolahan data ini menunjukkan bahwa variabel independen Kompleksitas Tugas tidak memiliki pengaruh signifikan terhadap variabel dependen Audit Judgment.

3. Pengalaman Audit (X3) tidak memiliki pengaruh signifikan terhadap Audit Judgment (Y). Hasil untuk Pengalaman Audit adalah nilai Estimate sebesar 0,849, nilai Wald sebesar 1,381 dan Significance sebesar 0,240 (> 0,5). Hasil pengolahan data ini menunjukkan bahwa variabel independen Pengalaman Audit tidak

\subsection{Pembahasan} memiliki pengaruh signifikan terhadap variabel dependen Audit Judgment.

Tekanan ketaatan mempengaruhi audit judgment secara signifikan. Semakin tinggi tekanan ketaatan yang dialami auditor, maka semakin menurun kualitas audit judgment yang dihasilkan. Ketika dihadapkan dengan pertanyaan menyangkut keinginan klien yang mengarah pada penyimpangan dari standar audit, sebagian besar dari para auditor yang menjadi responden untuk penelitian ini cenderung mengutamakan ketaatan terhadap peraturan dan standar audit dibandingkan mengikuti keinginan klien. Mereka lebih mengutamakan prinsip dalam pekerjaan mereka daripada mengikuti perintah klien untuk menjaga agar klien tidak berpindah ke instansi lain. Ketika dihadapkan dengan pertanyaan menyangkut perintah atasan yang lebih mengutamakan klien daripada ketaatan pada standar audit, kelompok responden yang sama juga memilih untuk menegakkan peraturan yang ada daripada menuruti perintah atasan yang mengarah pada penyimpangan.

Kompleksitas tugas tidak mempengaruhi audit judgment secara signifikan. Para auditor yang menjadi respoden dalam penelitian ini tidak menemukan kendala yang berarti dalam menuntaskan tugas. Hal ini dapat disebabkan karena instansi tempat para auditor bekerja tidak memiliki masalah dalam pembagian tugas. Sekalipun tugas tersebut sulit atau kompleks, para auditor dapat mengerjakannya dengan baik karena tugas-tugas yang diberikan cenderung jelas dan dapat dipahami.

Pengalaman audit tidak mempengaruhi audit judgment secara signifikan. Di satu sisi, para responden setuju bahwa seorang auditor dengan pengalaman yang memadai baik dari segi jangka waktu bekerja maupun dari segi banyaknya klien yang telah diaudit akan lebih mudah menentukan audit judgment yang baik.

\section{KESIMPULAN DAN SARAN}

\subsection{Kesimpulan}

1. Tekanan ketaatan memiliki pengaruh yang signifikan terhadap audit judgment.

2. Kompleksitas tugas dan pengalaman audit memiliki pengaruh yang tidak signifikan terhadap audit judgment.

\subsection{Saran}

1. Para auditor diharapkan mempertahankan prinsip mereka dalam mengikuti standar audit dan sikap skeptisisme mereka dalam mengaudit meskipun dihadapkan dengan pilihan yang membahayakan kelangsungan mereka. Para atasan instansi juga diharapkan dapat lebih memperhatikan sikap objektif terhadap para klien untuk menghindari situasi dimana klien mempengaruhi penilaian atasan dan para auditor.

2. Para auditor diharapkan tetap berhati-hati dalam mengerjakan tugas-tugas yang sulit.

3. Para auditor diharapkan terus melakukan tugas mereka dengan baik agar dapat memiliki pengalaman audit yang memadai di kemudian hari. 
4. Untuk penelitian berikut, diharapkan untuk memperhatikan jenis pertanyaan di dalam kuesioner dan memperbanyak jumlah responden agar dapat melakukan analisa dengan lebih baik.

\section{DAFTAR PUSTAKA}

Anugraheni, M. 2014. "Pengaruh Tekanan Ketaatan, Kompleksitas Tugas dan Pengalaman Auditor Terhadap Audit Judgment." Skripsi Jurusan Akuntansi Fakultas Bisnis Universitas Katolik Widya Mandala Surabaya. Unpublished.

Arens, Alvin A., James L. Loebbecke. 2003. Auditing: An Integrated Approach. New Jersey: Prentice Hall Inc.

Ayudia, S. 2015. "Pengaruh Tekanan Ketaatan, Pengetahuan dan Pengalaman Auditor Terhadap Audit Judgment dengan Kompleksitas Tugas Sebagai Variabel Moderating (Studi Empiris pada KAP Pekanbaru, Padang danＭedan).” Jom FEKON, 2(2):115.

Bonner, S. E. 1994. "A Model of the Effects of Audit Task Complexity." Accounting, Organizations and Society, 19 (3):213-234.

Engko, Cecilia dan Gudono, 2007. Pengaruh Kompleksitas Tugas dan Locus Of Control Terhadap Hubungan Antara Gaya Kepemimpinan dan KepuasanKerja Auditor. SNA $\mathrm{X}$ Makassar.

Indarto, 2011. Analisis Faktor-Faktor Yang Mempengaruhi Penghentian Prematur Atas Prosedur Audit. Jurnal Dinamika Sosial Ekonomi, 7:2.

Jamilah, dkk. 2007. Pengaruh Gender, Tekanan Ketaatan, dan Kompleksitas Tugas Terhadap Audit Judgment. Proceeding SNA X Universitas Hasanudin Makasar. AUEP-06.

Knoers dan Haditono. 1999. Psikologi Perkembangan: Pengantar Dalam Berbagai Bagian. Cetakan ke -12, Gajah Mada University Press. Yogyakarta.

Martinov-Bennie, N. and Pflugrath, G. 2008. "The Strength of an Accounting Firm's Ethical Environment and the Quality of Auditors' Judgments." Journal of Business Ethics, 87:237-253.

Mulyadi, 2002. Auditing, Buku Dua, Edisi Ke Enam. Salemba Empat, Jakarta.

Praditaningrum, A. S. 2012. "Analisis Faktor-faktor yang Berpengaruh Terhadap Audit Judgment (Studi Pada BPK RI Perwakilan Provinsi Jawa Tengah).” Fakultas Ekonomika dan Bisnis Universitas Diponegoro Semarang. Unpublished.

Sabaruddinsah, 2007. "Pengaruh Gender, Pengalaman Auditor, dan Kompleksitas Tugas terhadap Audit Judgment." Paradigma Vol. 8 No. 01.

Tielman, E.M.A. dan Pamudji. S.H,. 2012. Pengaruh Tekanan Ketaatan, Tekanan Anggaran Waktu, Kompleksitas Tugas, Pengertahuan dan Pengalaman Auditor Terhadap Audit Judgment. 